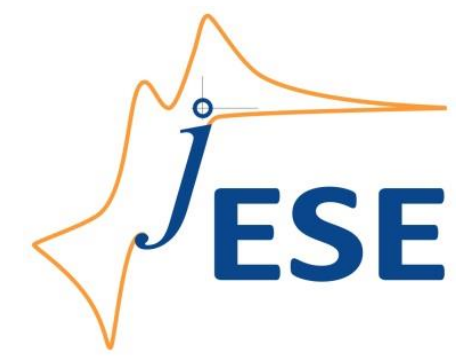

Open Access : : ISSN 1847-9286

www.jESE-online.org

Original scientific paper

\title{
Impedance aspect of charge storage at graphite and glassy carbon electrodes in potassium hexacyanoferrate (II) redox active electrolyte
}

Katja Magdić ${ }^{\bowtie}$, Višnja Horvat-Radošević, Krešimir Kvastek

Rudjer Bošković Institute, Bijenička c. 54, 10000 Zagreb, Croatia

${ }^{\square}$ Corresponding Author: : kmagdic@irb.hr; Tel.: +385-01-456-1152

Received: September 30, 2015; Accepted: February 10, 2016

\begin{abstract}
Different types of charge storage mechanisms at unmodified graphite vs. glassy carbon electrodes in acid sulphate supporting solution containing potassium hexacyanoferrate (II) redox active electrolyte, have been revealed by electrochemical impedance spectroscopy and supported by cyclic voltammetry experiments. Reversible charge transfer of $\mathrm{Fe}(\mathrm{CN}) 6^{3-/ 4-}$ redox reaction detected by assessment of $\mathrm{CVs}$ of glassy carbon electrode, is in impedance spectra indicated by presence of bulk diffusion impedance and constant double-layer/pseudocapacitive electrode impedance compared to that measured in the pure supporting electrolyte. Some surface retention of redox species detected by assessment of CVs of graphite electrode is in impedance spectra indicated by diffusion impedance coupled in this case by diminishing of double-layer/pseudocapacitive impedance compared to that measured in the pure supporting electrolyte. This phenomenon is ascribed to contribution of additional pseudocapacitive impedance generated by redox reaction of species confined at the electrode surface.
\end{abstract}

\section{Keywords}

Graphite; Glassy carbon; Ferri/ferrocyanide redox couple; Charge storage; Electrochemical impedance spectroscopy

\section{Introduction}

Except in electroanalytical and (bio)sensing fields where serve as standard redox probes for testing electrode activities [1,2], presence of a redox active couple in a supporting electrolyte solution has also been considered valuable in the field of electrochemical capacitors, EC, and supercapacitors, SC, [3-7]. Within this context of research, high redox reaction rate coupled with high electrode capacitances accomplished mostly by high surface-area carbon electrodes has been 
considered advantageous for EC/SC devices with improved charge storage properties. The main goal with using redox electrolyte is to increase the total charge capacity, $Q_{T}$, of the system, by adding the charge realised by redox reaction, $Q_{\text {redox, }}$ to already existing electrode double-

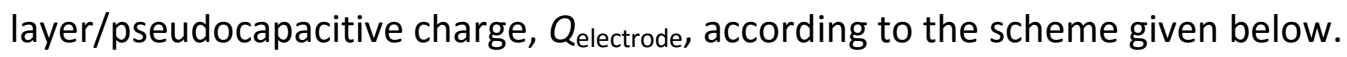

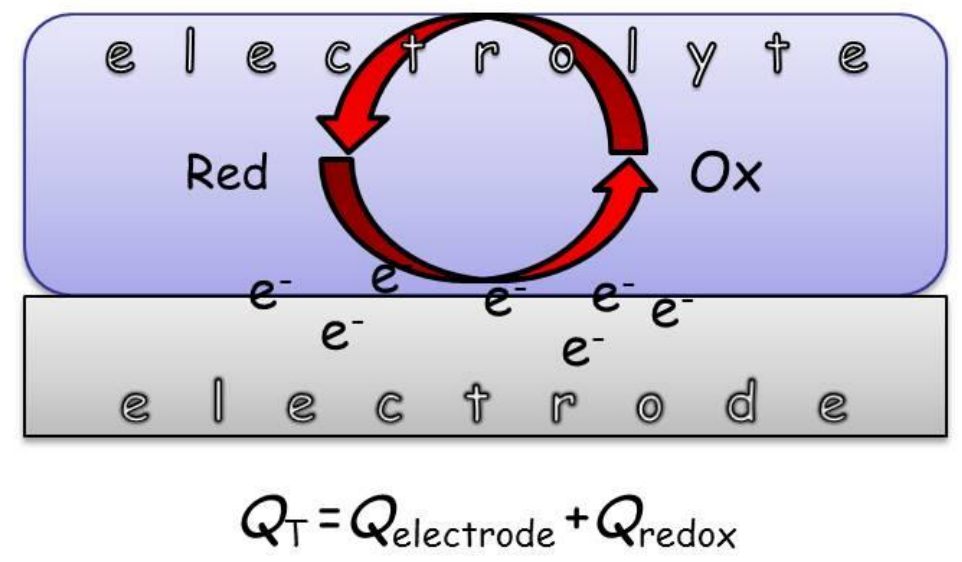

Scheme 1. Scheme of redox couple reaction at an electrode

Along with some other redox systems that have already been tested for such a purpose $[8,9]$, the ferro/ferricyanide, $\mathrm{Fe}(\mathrm{CN})_{6}^{3-/ 4-}$, redox couple was found useful due to high redox reaction rate and adequate standard redox potential $[5,10,11]$. Potassium hexacyanoferrate (II) and (III) are water soluble compounds, where negatively charged $\mathrm{Fe}(\mathrm{CN})_{6}{ }^{3-/ 4-}$ complex ions undergo one electron transfer oxidation/reduction interfacial reaction, requiring $9.63 \times 10^{4} \mathrm{C}$ per mol of reactants:

$$
\mathrm{Fe}^{\prime \prime}(\mathrm{CN})_{6}^{4-} \leftrightarrow \mathrm{Fe}^{\prime \prime \prime}(\mathrm{CN})_{6}{ }^{3-}+\mathrm{e}^{-}
$$

For a long time, the redox reaction R-1 has been considered a typical outer-sphere electron transfer reaction [12-14], what is inherently associated with fast electron transfer reaction controlled by mass transport of redox active species toward/from the electrode surface. In dependence not only on kind, concentration and $\mathrm{pH}$ of the supporting electrolyte, [15-17], but also on chemistry, morphology and electronic properties of a carbon electrodes, charge transfer can be suppressed, resulting in decreased rate of R-1 that becomes additionally controlled by electrolyte and/or electrode surface/bulk properties $[1,17,18]$.

Inherent complication with applying $\mathrm{Fe}(\mathrm{CN})_{6}{ }^{3-/ 4-}$ redox couple is relative instability of $\mathrm{Fe}^{\text {III }}(\mathrm{CN})_{6}{ }^{3-}$ complex ions, particularly in acid solutions [19]. $\mathrm{Fe}^{\text {III }}(\mathrm{CN})_{6}{ }^{3-}$ complex ions can also be destroyed in the course of electrochemical reaction $\mathrm{R}-1$ by forming the ferri-ferricyanide complex and insoluble ferri-ferrocyanide, $\mathrm{Fe}_{4}{ }^{\prime \prime \prime}\left[\mathrm{Fe}^{\prime \prime}(\mathrm{CN})_{6}\right]_{3}$ (Prussian Blue, PB) after subsequent reduction. It has already been shown that PB can be adsorbed at electrode surfaces spontaneously, at open circuit, or during potentiodynamic sweeps [20,21]. At favourable conditions, stable active layer of PB can be formed, showing prominent sensing, electrocatalytic and/or pseudocapacitive properties [19-21]. To avoid formation of PB, in majority of already published papers on electrochemical characterization of either separate high surface-porous carbon/Fe $(\mathrm{CN})_{6}{ }^{3-/ 4-}$ electrodes, or electrode assemblies into an $\mathrm{EC} / \mathrm{SC}$ device containing $\mathrm{Fe}(\mathrm{CN})_{6}{ }^{3-/ 4-}$ redox couple, experiments were performed in $\mathrm{pH}$ neutral supporting electrolyte solutions, using mostly cyclic voltammetry, CV and galvanostatic charging discharging electrochemical techniques. For some types of high surfaceporous carbon/Fe $(\mathrm{CN})_{6}{ }^{3-/ 4-}$ electrodes, voltage separations of redox peaks, ratios of anodic and cathodic peak currents and their dependences on scan potential rates showed the characteristics 
of reversible or quasi-reversible redox reaction kinetics [11,22-25]. These results, supported by discharge voltage plateaus in galvanostatic experiments [11,25], suggest that these types of carbon electrodes store charges as hybrid electrodes, exhibiting a combined effect of already high surface electrode double-layer capacitance and additional faradaic redox reaction [3,7]. For some other types of high surface-porous carbon/Fe $(\mathrm{CN})_{6}{ }^{3-/ 4-}$ electrodes, however, different voltammetric responses have been indicated by higher, sharper and narrower redox peaks and no discharge voltage plateaus in galvanostatic experiments $[10,26]$. Explanation was given in the terms of either surface adsorption of redox ions $[7,10]$ or retention of some amount of charges at the electrode surface or near-surface region by thin-layer electrochemistry, TLE [26]. TLE is usually accomplished with highly porous materials $[26,27]$ and its electrochemical response has been found equivalent to adsorption of reaction species at the electrode surface [26]. These results suggest that these types of carbon electrodes store redox charges at the electrode surface, exhibiting enhanced electrode capacitance through a pseudocapacitive effect $[3,7,28]$.

Although distinguishing between only diffusion and adsorption/TLE controlled redox reaction kinetics can easily be performed by electrochemical impedance spectroscopy, EIS, technique [28], EIS has been applied sporadically in this field, giving mostly superficial information $[9,11,15,25]$. Herein, in addition to ordinary CV experiments, the results of measurements and analysis of impedance spectra measured at graphite and glassy-carbon electrodes in the supporting electrolyte containing $\mathrm{Fe}(\mathrm{CN})_{6}{ }^{3-/ 4-}$ redox couple will be presented. In spite of possible complications due to PB formation, $0.5 \mathrm{~mol} \mathrm{dm}^{-3} \mathrm{H}_{2} \mathrm{SO}_{4}$ was chosen for the supporting electrolyte due to its enormous effect on enhancement of specific capacitance/pseudocapacitance values of carbon electrodes $[1,3,30]$.

\section{Experimental}

All experiments were performed in conventional three-electrode cell, filled with $0.5 \mathrm{~mol} \mathrm{dm}^{-3}$ $\mathrm{H}_{2} \mathrm{SO}_{4}$ (pH 0.6) supporting electrolyte. Balanced quantities of $\mathrm{K}_{4} \mathrm{Fe}(\mathrm{CN})_{6} \times 3 \mathrm{H}_{2} \mathrm{O}$ (potassium hexacyanoferrate (II)) (Sigma-Aldrich Inc.) were added directly into the cell to give the final concentration of $5 \times 10^{-3} \mathrm{~mol} \mathrm{dm}^{-3}$. Electrochemical measurements were performed in absence and presence of always freshly prepared $\mathrm{K}_{4} \mathrm{Fe}(\mathrm{CN})_{6} / \mathrm{H}_{2} \mathrm{SO}_{4}$ solution. High purity $\left(18 \times 10^{6} \Omega \mathrm{cm}\right)$ water was used for all solution preparations.

Graphite, G, (Goodfellow, UK) and glassy carbon, GC, (EG\&G, USA) electrodes, sealed in glass tubes and exposing $0.07 \mathrm{~cm}^{2}$ and $0.03 \mathrm{~cm}^{2}$ of respective geometrical surfaces and put vertically in the cell served as the working electrodes, WE. High surface platinum spiral in a separate compartment and saturated calomel electrode, SCE, (Radiometer, Denmark) equipped with a Haber-Luggin cappilary and the Pt wire pseudo-reference electrode [31] were used as the counter and reference electrodes, respectively. All potentials are reported with respect to the SCE. Prior measurements, WE surfaces were hand polished, sonicated in ultrapure water and slightly preconditioned in $0.5 \mathrm{~mol} \mathrm{dm}^{-3} \mathrm{H}_{2} \mathrm{SO}_{4}$, by applying 10 potential cycles between -0.30 and $1.60 \mathrm{~V}_{\text {SCE }}$ and scan rate of $10 \mathrm{mV} \mathrm{s}^{-1}$. The pre-condition procedure always ends at $-0.30 \mathrm{~V}_{\text {SCE }}$ where the WE was left for at least 15 min prior further experiments [32,33].

Impedance spectroscopy, EIS, and cyclic voltammetry, CV, experiments were carried out in nonstirred electrolyte solutions, at ambient temperature of $25 \pm 2{ }^{\circ} \mathrm{C}$ and oxygen free atmosphere maintained by blowing nitrogen through electrolyte solution prior measurements. CV experiments were employed by the $1287 \mathrm{ECl}$ under $Z_{\text {corr }}$ software (Scribner Assoc. Inc.) control in monitoring the current-voltage profiles performed in two potential scans between -0.20 and $1.05 \mathrm{~V}_{\text {SCE }}$ and 
different scan rates $\left(5-250 \mathrm{mV} \mathrm{s}^{-1}\right)$. EIS data were measured with $1260 \mathrm{FRA}$ and $1287 \mathrm{ECl}$ (Solartron, UK) under $Z_{\text {plot }}$ software (Scribner Assoc. Inc.) control. Sine wave ac signal of $10 \mathrm{mV}$ amplitude, frequency, $f$, ranged between $10^{5} \mathrm{~Hz}$ and $0.02 \mathrm{~Hz}$ and $5-10$ frequency points measured per decade were applied at different bias potentials. Contributions of experimental artefacts were corrected as before [33].

\section{Results and discussion}

\section{Cyclic voltammograms of $\mathrm{GC}$ and $\mathrm{G}$ electrodes in $\mathrm{H}_{2} \mathrm{SO}_{4} / \mathrm{K}_{4} \mathrm{Fe}(\mathrm{CN})_{6}$ redox electrolyte}

Representative CVs of glassy carbon, GC and graphite, $\mathrm{G}$ electrodes in $0.5 \mathrm{~mol} \mathrm{dm}{ }^{-3} \mathrm{H}_{2} \mathrm{SO}_{4}$ containing $5 \times 10^{-3} \mathrm{~mol} \mathrm{dm}^{-3} \mathrm{~K}_{4} \mathrm{Fe}(\mathrm{CN})_{6}$, recorded between -0.20 and $1.05 \mathrm{~V}_{\mathrm{SCE}}$ for the scan rates, $v$, changed between 250 and $5 \mathrm{mV} \mathrm{s}^{-1}$ are presented in Figure $1 \mathrm{a}$.

a)
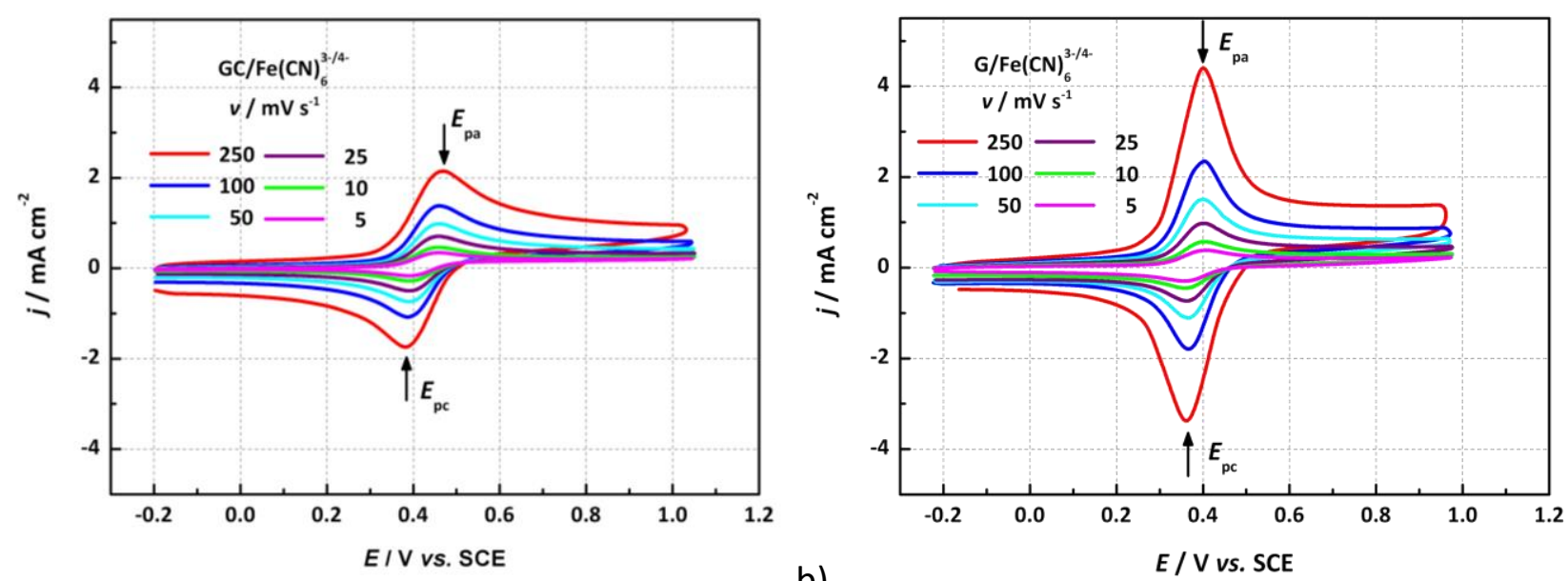

b)
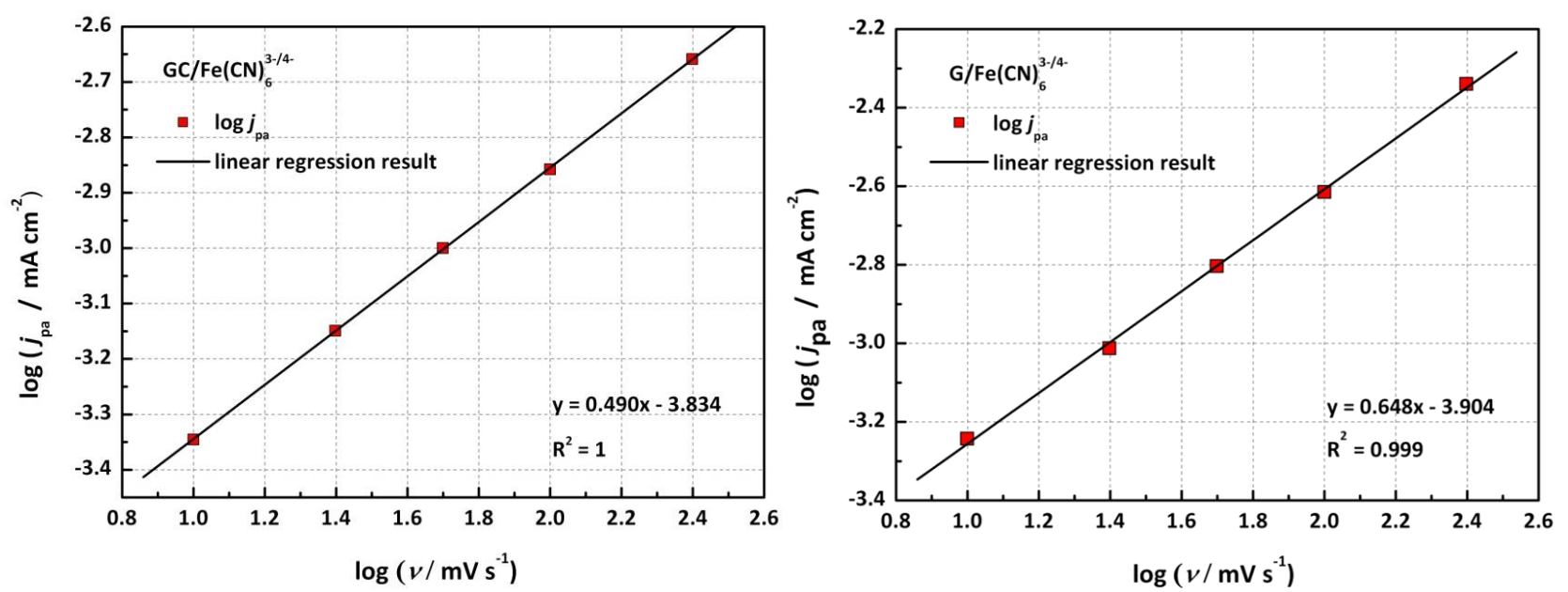

Figure 1. a) CVs (at denoted v) and b) $\log \mathrm{j}_{p a} \mathrm{vs}$. $\log v$ curves of GC and $G$ electrodes in $0.5 \mathrm{~mol} \mathrm{dm}^{-3} \mathrm{H}_{2} \mathrm{SO}_{4} / 5 \times 10^{-3} \mathrm{~mol} \mathrm{dm}^{-3} \mathrm{~K}_{4} \mathrm{Fe}(\mathrm{CN})_{6}$ electrolyte solution

Well shaped $j-E$ curves with a pair of prominent peaks, $E_{\mathrm{pa}}$ and $E_{\mathrm{pc}}$, situated at about $0.40 \mathrm{~V}_{\mathrm{SCE}}$ are presented for both carbon electrodes in Figure 1a. Relatively positive value of peak potential, $\left(E_{\mathrm{pa}}+E_{\mathrm{pc}}\right) / 2$, defining the formal redox potential, $E^{0}$, of the $\mathrm{Fe}(\mathrm{CN})_{6}{ }^{3-}$ redox couple in the given electrolyte solution, can be related to the electrolyte of higher ionic strength [16,34]. The shapes of peaks of two carbon electrodes are rather different, showing sharper shapes and higher peak current densities values $\left(j_{\mathrm{pa}}\right.$ and $\left.j_{\mathrm{pc}}\right)$ for $\mathrm{G}$ electrode, as opposed to wider peaks and lower $j_{\mathrm{pa}}$ and $j_{\mathrm{pc}}$ 
values for $\mathrm{GC}$ electrode. Peak separation values, $\Delta E_{\mathrm{pp}}=\left(E_{\mathrm{pa}}-E_{\mathrm{pc}}\right)$, usually utilized to assess electron transfer activities [1,35] are $70 \mathrm{mV}$ (at all $v$ ) for GC electrode and between 36 and $45 \mathrm{mV}$ (dependent on $v$ ) for $\mathrm{G}$ electrode, respectively. Slopes of the power law relationship between log of peak current density, $j_{\mathrm{pa}}$, and log $v$ are shown in Figure $1 \mathrm{~b}$. The values of slopes were calculated as 0.49 for $\mathrm{GC}$ and 0.65 for $\mathrm{G}$ electrode, respectively. Note that $\Delta E_{\mathrm{pp}}=57 \mathrm{mV}$ for one electron transfer and slope $=\left(\mathrm{d} \log j_{\mathrm{pa}} / \mathrm{dlog} v\right)=0.5$ have already been theoretically predicted for ideally reversible redox reaction with mass transport (diffusion) controlled kinetics, while $\Delta E_{\mathrm{pp}}=0$ and $\left(\right.$ d log $\left.j_{\mathrm{pa}} / \mathrm{dlog} v\right)=1$ are predicted for fully confined redox species resulting in pseudocapacitance. A mixed process is predicted for all slopes (dlog $j_{\mathrm{pa}} / \mathrm{d} \log v$ ) found between 0.5 and $1[3,35]$. Consequently, the results presented in Figure 1 indicate almost reversible, diffusion controlled kinetics of $\mathrm{Fe}(\mathrm{CN})_{6}{ }^{3-/ 4-}$ redox reaction at $\mathrm{GC}$ electrode and a mixed process including some retention of redox active species at the G electrode surface, respectively. CVs similar to that of GC electrode presented in Figure 1a, denoting reversible or quasy-reversible reaction kinetics, have already been reported not only for slightly modified GC electrode [36], but also for micro-bundles of multi-walled carbon nanotubes [22], porous diamond [23], porous boron-doped diamond/carbon nanotubes [24], graphene paper [11] and reduced graphene oxide sheets electrodes [25]. At the other side, CVs similar to that of $\mathrm{G}$ electrode presented in Figure $1 \mathrm{~b}$, indicating some retention of electroactive species at the electrode surface were already observed for activated carbon [10] and vertical arrays of macroporous single-walled carbon nanotube electrodes [26].

\section{Impedance spectra of $\mathrm{GC}$ and $\mathrm{G}$ electrodes in $\mathrm{H}_{2} \mathrm{SO}_{4} / \mathrm{K}_{4} \mathrm{Fe}(\mathrm{CN})_{6}$ redox electrolyte}

Impedance spectra of glassy carbon, GC, and graphite, G, electrodes measured in $0.5 \mathrm{~mol} \mathrm{dm}^{-3}$ $\mathrm{H}_{2} \mathrm{SO}_{4} / 5 \times 10^{-3} \mathrm{~mol} \mathrm{dm}^{-3} \mathrm{~K}_{4} \mathrm{Fe}(\mathrm{CN})_{6}$ electrolyte solution are presented in Figure 2. Bode (log $|Z|$ and $\varphi$ vs. $\log \omega)$ plots are presented for $E=0.30,0.40$ and $0.50 \mathrm{~V}_{\mathrm{SCE}}(c f$. Figure 1a). $|\mathrm{Z}|$ is impedance magnitude, $\varphi$ is phase angle while $\omega=2 \pi f$ is angular frequency.

As is seen in Figure 2, Bode plots of both carbon electrodes are of similar values and also of similar frequency responses at the same potential values. At high to medium frequencies, both impedance spectra show resistive $\left(\log |Z|\right.$ slopes $\approx 0$ and $\left.\varphi \approx 0^{\circ}\right)$ to capacitive responses $((\log |Z|$ slopes $\approx$ -1 and $\varphi \rightarrow-90^{\circ}$ ), what is typical for electrolyte resistance and double-layer capacitive impedance responses [29]. At lower frequencies, however, the shapes of Bode plots in Figure 2 becomes typical for semi-infinite diffusion controlled faradaic reaction ( $\log |Z|$ slopes $\rightarrow-0.5$ and $\varphi \rightarrow-45^{\circ}$ ) [29], what for both electrodes become the most prominent at $E=E^{0}=0.40 \mathrm{~V}_{\mathrm{SCE}}$ ( $c f$. Figure 1a).

The shifts of capacitive impedance lines in $\log |Z|$ and $\varphi$ curves in Bode plots in Figure 2, are evident for both electrodes, but are more prominent for G vs. GC electrode. These shifts indicate changes in double-layer capacitive impedance values at different potentials, what has already been noticed for various types of carbon electrodes [32,33,37,38]. Potential dependence of double-layer capacitance values of carbon electrodes is commonly observed phenomenon being usually ascribed to potential dependent pseudocapacitance, generated by fast redox reaction(s) of oxygen containing species formed inherently and more profoundly in acid solutions and/or strongly electrochemically modified carbon surfaces $[1,3,12,32,33,39]$. For here explored GC and G electrodes, potential dependences of capacitive impedances were recorded in the pure supporting electrolyte $\left(0.5 \mathrm{~mol} \mathrm{dm}^{-3} \mathrm{H}_{2} \mathrm{SO}_{4}\right)$ and in the form of Bode plots presented in Figure 3.

In agreement with previous reports [32,33,37], Bode plots of GC electrode in Figure 3 changed with potential, showing lower capacitive impedances (higher capacitance values) at 0.30 and $0.40 \mathrm{~V}_{\mathrm{SCE}}$ than $0.50 \mathrm{~V}_{\mathrm{SCE}}$. 

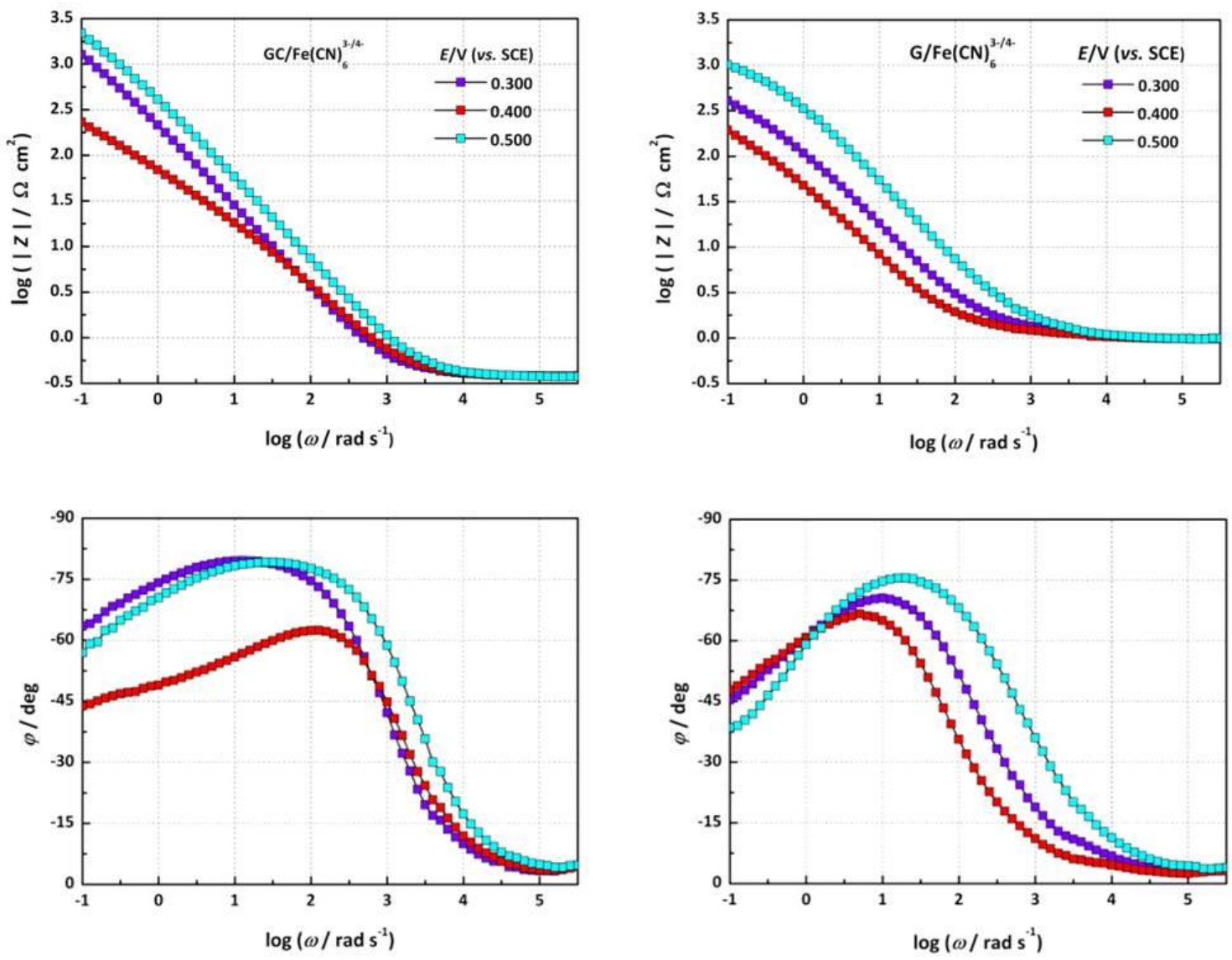

Figure 2. Bode plots measured at denoted potential values of $G C$ and $G$ electrodes in $0.5 \mathrm{~mol} \mathrm{dm}^{-3} \mathrm{H}_{2} \mathrm{SO}_{4} / 5 \times 10^{-3} \mathrm{~mol} \mathrm{dm}^{-3} \mathrm{~K}_{4} \mathrm{Fe}(\mathrm{CN})_{6}$. electrolyte solution
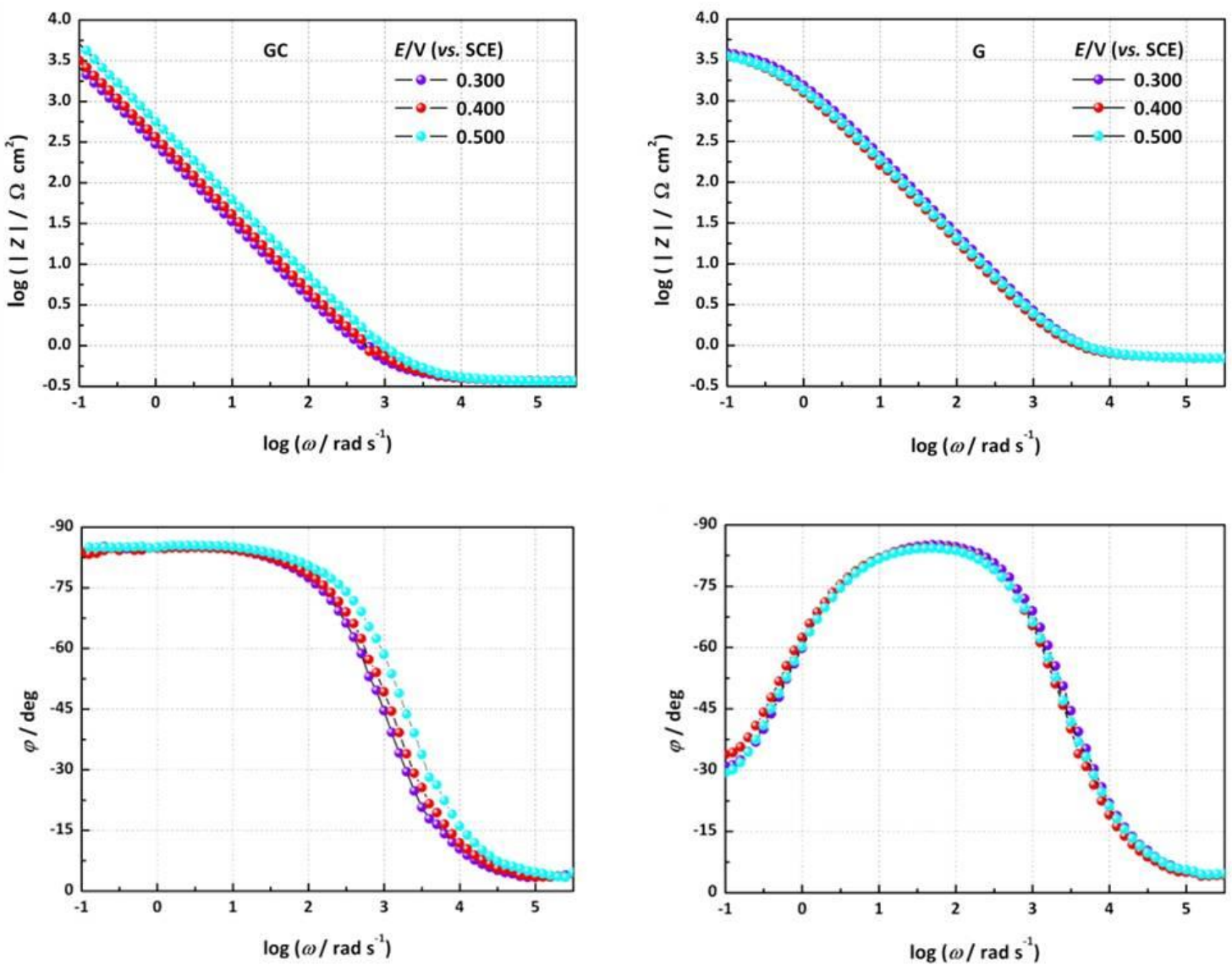

Figure 3. Bode plots measured at denoted potential values of GC and $G$ electrodes in $0.5 \mathrm{~mol} \mathrm{dm}^{-3} \mathrm{H}_{2} \mathrm{SO}_{4}$ electrolyte solution 
This has to be ascribed to the fast faradaic reaction of redox active surface carbon oxygen containing species identified as hydroquinone/quinone redox couple with $E^{0}=0.35 \mathrm{~V}_{\text {SCE }}$ in acid sulphate electrolyte $[3,12,32,33]$. For $G$ electrode, however, impedance spectra are not fully capacitive ( $c f$. change of slope of capacitive impedance line and decrease of $\varphi$ values at the lowest frequencies) what can be ascribed to different morphologies and inherent porosity of slightly modified G vs. slightly modified GC electrode surface [40]. Anyhow, capacitive impedances that are dominant at medium to low frequencies in impedance spectra of $G$ electrode in Figure 3 , are almost unchanged at given potentials, suggesting that capacitive shifts of Bode plots presented in Figure 2 should be ascribed to presence of the $\mathrm{Fe}(\mathrm{CN})_{6}{ }^{3-/ 4-}$ redox couple in electrolyte solution. In Figure 4, Bode plots measured at $E=0.40 \mathrm{~V}_{S C E}$ in either pure supporting electrolyte solution or solution containing $\mathrm{Fe}(\mathrm{CN})_{6}{ }^{3-/ 4-}$ redox couple can be compared for each electrode.
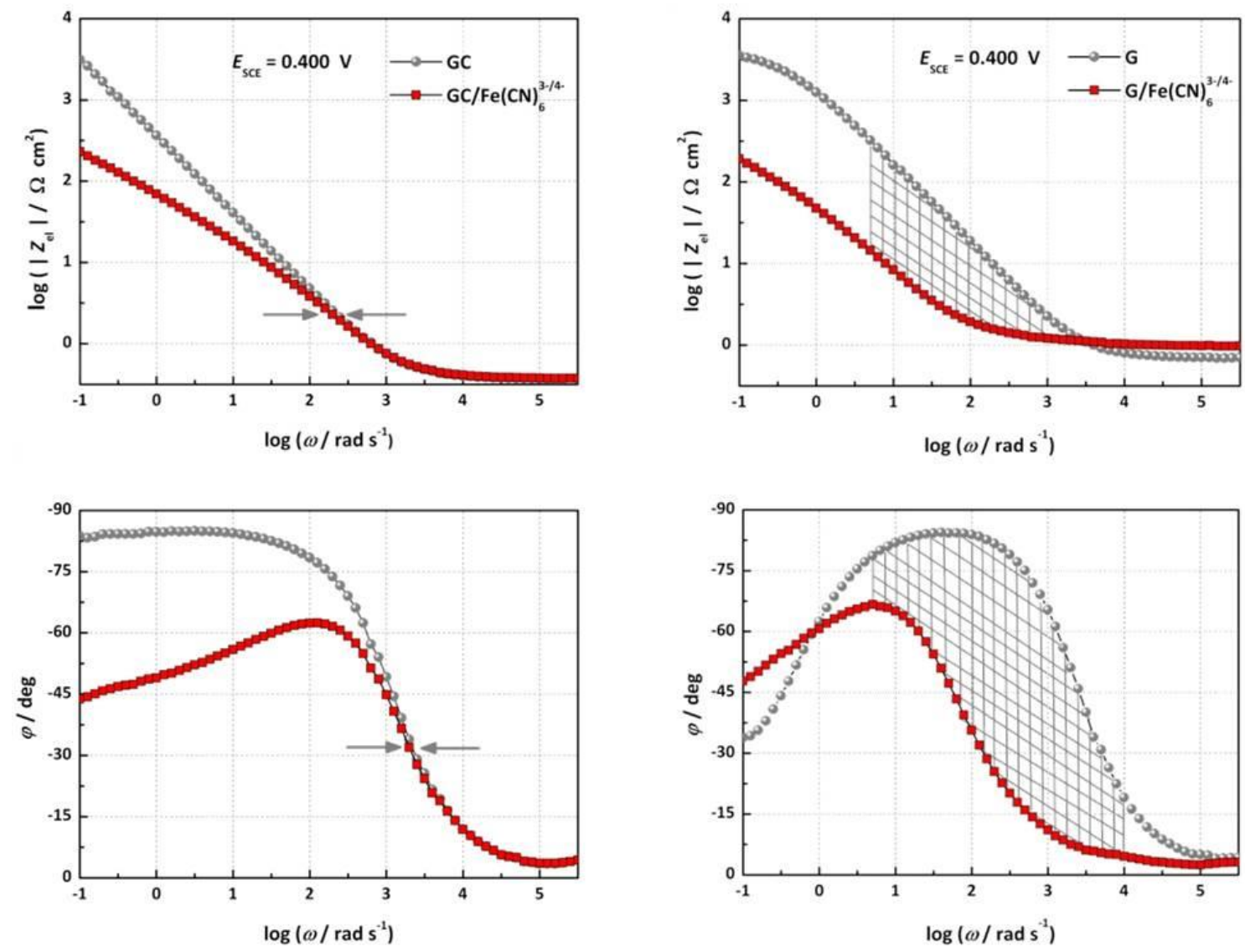

Figure 4 Bode plots of GC and G electrodes measuredat $E=0.40 \mathrm{~V}_{S C E}$ in $0.5 \mathrm{~mol} \mathrm{dm} \mathrm{m}_{2}^{-3} \mathrm{HO}_{4}$ and $0.5 \mathrm{~mol} \mathrm{dm}^{-3} \mathrm{H}_{2} \mathrm{SO}_{4} / 5 \times 10^{-3} \mathrm{~mol} \mathrm{dm}^{-3} \mathrm{~K}_{4} \mathrm{Fe}(\mathrm{CN})_{6}$ electrolyte solutions.

Whereas for the GC electrode, Bode plots in Figure 4 do not show differences between capacitive impedance responses measured in absence and presence of $\mathrm{Fe}(\mathrm{CN})_{6}{ }^{3-/ 4-}$ redox couple (cf. perfect matches of two capacitive lines and $\varphi$ plots denoted by arrows in Figure 4), for $G$ electrode, however, there is a significant decrease of capacitive impedance (increase of capacitance) of the spectrum measured in the presence of redox couple, compared to that measured in pure supporting electrolyte (denoted by shaded area in Figure 4). Increase of capacitive impedance in the supporting electrolyte containing redox couple suggest some interaction of $\mathrm{Fe}(\mathrm{CN})_{6}{ }^{3-/ 4-}$ ions with the $\mathrm{G}$ electrode, that in turn has not been observed for the GC electrode surface.

Charge storage on $\mathrm{GC}$ and $\mathrm{G}$ electrodes in $\mathrm{H}_{2} \mathrm{SO}_{4} / \mathrm{K}_{4} \mathrm{Fe}(\mathrm{CN})_{6}$ redox electrolyte

The results and discussion on CVs shown in Figure 1 and impedance spectra shown in Figs. 2-4 pointed to different charge storage mechanisms of R-1 at GC and G electrodes, respectively. The 
obtained result for GC electrode suggest that R-1 is proceeding as a reversible, bulk diffusion controlled faradaic reaction with the electrode surface serving only as a source/sink of electrons. For this type of reaction, the total charge, $Q_{T}(c f$. Scheme 1$)$ is stored by a combined effect of already high electrode double-layer capacitance/pseudocapacitance and additional faradaic redox reaction realising the charge, $Q_{\text {redox, }}$ stored by the amount of reactants present in the bulk of electrolyte solution $[3,7,28]$. For $G$ electrode, however, the obtained results suggest that R-1 is proceeding partly as a reversible, bulk diffusion controlled faradaic reaction and partly by surface confined species generating a pseudocapacitive effect. Irrespectively to the origin of confinement that can be adsorption, TLE or PB formation, the rate of R-1 is affected by the amount of surface confined species. For this type of reaction, the realised $Q_{\text {redox }}$ is stored partly on the electrode surface and partly in the bulk of electrolyte solution, what has generally been considered more beneficial from the EC/SC-specific power point of view $[3,7,28]$.

\section{Conclusions}

The present study has demonstrated the efficient application of electrochemical impedance spectroscopy technique in evaluation of the charge storage mechanisms of the $\mathrm{Fe}(\mathrm{CN})_{6}{ }^{3-/ 4-}$ redox reaction on unmodified $\mathrm{GC}$ and $\mathrm{G}$ electrodes. Even qualitative analysis of impedance Bode plots measured at, or near formal redox potential of $\mathrm{Fe}(\mathrm{CN})_{6}{ }^{3-/ 4-}$ redox couple in acid sulphate electrolyte solution pointed to some differences between impedance responses of two electrodes. Whereas the bulk diffusion impedance, indicating almost reversible redox reaction has been detected in impedance spectra of both electrodes, significant diminishing of capacitive impedance, compared to that measured in pure supporting electrolyte has been detected for the $G$ electrode only.

Differences in capacitive contributions in impedance spectra pointed directly to different charge storage mechanisms at two electrodes. Almost constant capacitance of GC electrode in impedance spectra measured in either pure supporting electrolyte or in electrolyte containing $\mathrm{Fe}(\mathrm{CN})_{6}{ }^{3-/ 4-}$ redox couple does not indicate any interactions between electrode surface and electroactive species in electrolyte solution. Contrary to that, significant increase of electrode capacitance of $\mathrm{G}$ electrode capacitance of $\mathrm{G}$ electrode in the electrolyte containing redox couple points to high extent of interaction between electrode surface and electroactive species in the solution. This interaction is manifested through confinement of some amount of electroactive species at the electrode surface and their fast redox reaction resulting in a pseudocapacitance.

All the conclusions derived on the basis of impedance spectra evaluations are fully supported by the results of cyclic voltammetry experiments.

Acknowledgement: This work is supported by the Croatian Science Foundation under the project ESUP-CAP (0-1673-2014).

\section{References}

[1] R. L. McCreery, Chem. Rev. 108 (2008) 2646-2687.

[2] R. O. Kadara, N. Jenkinson, C. E. Banks, Sensors and Actuators B 138 (2009) 556-562.

[3] B. E. Conway, Electrochemical Supercapacitors: Scientific fundamentals and technological applications, Kluwer Acad./Plenum Pub. New York. 1999.

[4] S. Roldán, C. Blanco, M. Granda, R. Menéndez, R. Santamaría, Angew. Chem. 123 (2011) 1737-1739.

[5] S. T. Senthilkumar, R. Kalai Selvan, J. S. Melo, J. Mater. Chem. A 1 (2013) 12386-12394.

[6] K. Fic, M. Meller, E. Frackowiak, J. Electrochem. Soc. 162 (2015) A5140-A5147.

[7] B. Akinwolemiwa, C. Peng, G. Z. Chen, J. Electrochem. Soc. 162 (2015) A5054-A5059. 
[8] S. Roldán, M. Ganda, R. Menéndez, R. Santamaría, C. Blanco, J. Phys. Chem. C 115 (2011) 17607-17611.

[9] S. T. Senthilkumar, R. Kalai Selvan, N. Ponpandian, J. S. Melo, Y. S. Lee, J. Mater. Chem. A 1 (2013) 7913-7919.

[10] Y. Tian, J. Yan, R. Xue, B. Yi, Capacitive properties of activated carbon in $\mathrm{K}_{4} \mathrm{Fe}(\mathrm{CN})_{6}$, J. Electrochem. Soc., 158 (2011) A818-A821.

[11] K. Chen, F. Liu, D. Xue, S. Komarneni, Nanoscale 7 (2015) 432-439.

[12] L. Otero, N. Vettorazzi, L. Sereno, J. Electrochem. Soc. 148 (2001) E413-E418.

[13] I. Duo, A. Fujishima, Ch. Comninellis, Electrochem. Commun. 5 (2001) 695-700.

[14] D. Becker, K. Jüttner, The impedance of fast charge transfer reactions on boron doped diamond electrodes. Electrochim. Acta, 49 (2003) 29-39.

[15] P. Papakonstantinou, R. Kern, L. Robinson, H. Murphy, J. Irvine, E. McAdams, J. McLaughlin, Fullerenes, Nanotubes and Carbon Nanostructures 13 (2005) 91-108.

[16] N. G. Tsierkezos, U. Ritter, Phys. Chem. Liquids 50 (2012) 661-668.

[17] M. C. Granger, G. M. Swain, J. Electrochem. Soc. 146 (1999) 4551-4558.

[18] X. Ji, C.E. Banks, A. Crossley, R.G. Compton, Chem. Phys. Chem. 7 (2006) 1337-1344.

[19] A. A. Karyakin, Electroanalysis 13 (2001) 813-819.

[20] Y. Ding, G. Gu, X.-H. Xia, J. Solid State Electrochem. 12 (2008) 553-558.

[21] F. Ricci, G. Palleschi, Biosens. Bioelectron. 21 (2005) 389-407.

[22] J. M. Nugent, K. S. V. Santhanam, A. Rubio, P. M. Ajayan, Nano Lett. 1 (2001) 87-91.

[23] K. Honda, M. Yoshimura, R. Uchikado, T. Kondo, T. N. Rao, D.A. Tryk, A. Fujishima, M. Watanabe, K, Yasui, H. Masuda, Electrochim. Acta 47 (2002) 4373-4385.

[24] H. Zanin, P.W. May, D.J. Fermin, D. Plana, S. M. C. Vieira, W. I. Milne, E. J. Corat, ACS Appl. Mater. Interface 6 (2014) 990-995.

[25] J. Yang, S. Gunasekaran, Carbon 51 (2013) 36-44.

[26] R. Narayanan, P. R. Bandaru, J. Electrochem. Soc. 162 (2015) A86-A91.

[27] C. Punckt, M. A Pope, A. Aksay, J. Phys. Chem. C 117 (2013) 16076-16086.

[28] T. Brousse, D. Bélanger, J. W. Long, J. Electrochem. Soc. 162 (2015) A5185-A5189.

[29] M. Sluyters-Rehbach, J.H. Sluyters, Sine wave methods in the study of electrode processes, M. Dekker, New York, 1970.

[30] C. Zhong, X. Deng, W. Hu, J. Qiao, L. Zheng, J. Zhang, Chem. Soc. Rev. (2015). Doi: 10.1039/c5cs00303b.

[31] V. Horvat-Radošević, K. Kvastek, J. Electroanal. Chem. 591 (2006) 217-222.

[32] M. G. Sullivan, R. Kötz, O. Haas, J. Electrochem. Soc. 147(1) (2000) 308-317.

[33] K. Magdić, K. Kvastek, V. Horvat-Radošević, Electrochimica Acta 117 (2014) 310-321.

[34] D. J. Kim, J. Wang, J. Yang, H. W. Kim, G. M. Swain, J. Phys. Chem. C 115 (2011) 10026-10032.

[35] R. G. Compton, C. E. Banks, Understanding voltammetry, World.Sci.Pub.Co.Pte.Ltd., 2007.

[36] P. Heiduschka, J. Dittrich, Electrochim. Acta 37 (1992) 2573-2580.

[37] S. I. Stevanović, V. V. Panić, A. B. Dekanski, A. V. Tripković, V. M. Jovanović, Phys. Chem. Chem. Phys. 14 (2012) 9475-9485.

[38] K. Magdić, K. Kvastek, V. Horvat-Radošević, Acta Chim. Slov. 61 (2014) 366-375.

[39] H. Xu, X. Fan, Y. Lu, L. Zhong, X. Kong, J. Wang, Carbon 48 (2010) 3300-3303.

[40] K. Magdić, Electrochemical impedance spectroscopy in characterization of unmodified and electrochemically modified carbon electrodes, Ph.D.Thesis, University of Zagreb, 2014.

(c) 2016 by the authors; licensee IAPC, Zagreb, Croatia. This article is an open-access article distributed under the terms and conditions of the Creative Commons Attribution license (http://creativecommons.org/licenses/by/4.0/) 